\title{
Apresentando Alphonse Allais
}

\author{
Edmond B. J. J. Thauront
}

Alphonse Allais era natural de Honfleur, nascido a 20 de outubro de 1854 (no mesmo dia que Arthur Rimbaud, quatro dias depois de Oscar Wilde). Filho de um farmacêutico (o que na época significava boticário, químico, e personagem importante das pequenas comunidades interioranas), foi para Paris aos 18 anos para fazer estudos de farmácia que nunca concluiu. Por outro lado, nunca os interrompeu também, e por toda a vida manteve intensas relações com a ciência de seu tempo, normalmente para debochar, mas também como colaborador de Charles Cros nos seus trabalhos sobre a fotografia policrômica. Nos cinco primeiros anos que ele passou na capital, Allais parece ter dedicado mais tempo às festas, bebedeiras, paqueras e viradas de noites, enfim, à boemia, do que a qualquer outra atividade.

Contudo, ele já escrevia pequenas "fantasias" que vendia para outros, ou que produzia sob pseudônimo. Ele publica um primeiro conto assinando o próprio nome aos 21 anos, em 1875, cujo título é Salmigondis, num jornal de estudantes, o Tintamarre. Aos poucos, a sua assinatura foi aparecendo, em plaquetas de monólogos, fábulas, sentenças, provérbios, cúmulos e falsas entrevistas nos diversos jornais humorísticos que pululavam então em Paris. Allais já debochava de tudo e de todos, e parece que os únicos escritores que ele realmente respeitava eram Michel de Montaigne e Charles Baudelaire. As outras glórias nacionais eram passadas na lixa, e muitas vezes não restava muito depois de Allais meter o seu bedelho. Assim, La Fontaine, Vitor Hugo e Guy de Maupassant eram algumas vítimas preferenciais de seu escárnio. Outros - o general de brigada Poilloüe de Saint Mars, o economista Paul Leroy Beaulieu e o crítico de arte Franscique Sarcey, por exemplo -, que seriam hoje totais desconhecidos se não tivessem sido chacoteados por Allais, ficaram na memória pelo modo magistral que Allais os "pastichava". Isto foi tão longe que, quando outro humorista quis imitar o estilo 
bonachão de Sarcey, quem protestou foi o próprio Allais, em carta aberta: "Só duas pessoas têm o direito de assinar Sarcey: o próprio Sarcey e eu mesmo!"’1. (ALLAIS, 1990: XXVI)

O nome de Allais foi crescendo, com a publicação de um número cada vez maior de contos e crônicas semanais em numerosos jornais, que ele mesmo reuniu em uma dúzia de coletâneas, publicadas de 1891 a 1902, e que não representam a metade de suas obras completas (mais de 1500 contos e/ou crônicas). Foi redator-chefe da revista do Chat Noir de 1885 a 1891 e do jornal Sourire de 1899 até a sua morte, a 28 de outubro 1905, uma semana após ter completado 51 anos, de flebite mal tratada.

Naquela época, além de abrir as suas colunas a jovens talentos (Maurice Curnonsky, Sacha Guitry, Franc-Nohain, Gabriel de Lautrec ou Blaise Petiveau; também "descobriu" Eric Satie e o batizou de Ésotéric Satie), Allais também trabalhava em numerosas colaborações, e algumas obras póstumas foram publicadas com Jehan Soudan, Tristan Bernard e Capus. Acabou tomando a frente da cena do humor francês nos seus quinze últimos anos de vida, numa época bem provida de "divertidores": Henri Monnier, Georges Courteline, Sapeck, Georges Auriol, Mac-Nab, Eugène Chavette, Mac Astrol, Jules Jouy, Maurice Donnay, Cami, Alfred Capus, Christophe, mas também Verlaine, Charles Cros, Villiers de l'Isle-Adam, Claude Debussy que, sem serem humoristas confessos, se compraziam em chocar a sociedade francesa da virada do século. Como escreveu Jean Claude Carrière, numa bela homenagem: "Todas [as vertentes do humor do fim do século XIX] convergem em direção a Allais. Os outros são os rios, ele é o mar”’. (CARRIÈRE, 1988: 363).

Allais não foi somente um precursor da prosa. Segundo François Caradec, qualquer francófono do século XX que tenha tratado de versos holorimos (que rimam do começo ao fim), neo-alexandrinos, rimas ricas para o olho (falsas rimas) e toda uma plêiade de exercícios de estilo lhe tem verdadeira reverência. Todos os "torturadores" da língua francesa devem algo a Allais, muitas vezes muito: Bobby Lapointe, Raymond Devos, Robert Desnos, Francis Blanche e Pierre Dac, e mais recentemente Antoine De Cones, e muitos outros cuja lista exaustiva é impossível de ser redigida, por ingressarmos nas vielas da subjetividade.

1 Deux personnes seulement [...] ont le droit de signer Sarcey: moi d'abord, et ensuite M. Francisque Sarcey (tradução nossa).

2 Tout converge vers lui. Les autres sont des fleuves. Il est la mer (tradução nossa). 
Patacessor (patafísico antes da hora), pré-oulipiano, Allais foi reconhecido até pelo grupo matemático Bourbaki, através de seu conterrâneo de Honfleur, o outro "monstro" da literatura que é Raymond Quenaud.

Precursor da pintura monocromática, trinta anos antes de Kasimir Malevitch e setenta antes de Yves Klein (que reconheceu a influência de Allais nas suas obras), Allais compôs o primeiro exemplo de composição musical de pausas (antecedendo os trabalhos de John Cage e Erwin Schulhoff), intitulado "Marcha fúnebre para o funeral de um grande músico surdo (pois as grandes dores são mudas)".

Ainda assim, Alphonse Allais talvez seja o autor francês do fim do século XIX menos conhecido dos leitores brasileiros. Que eu saiba, nunca uma tradução dele foi publicada em terras brasileiras. As raras traduções lusas que tive em mãos eram deploráveis, e, para dizer a verdade, quase incompreensíveis.

Os acasos da vida fizeram de mim ao mesmo tempo um bilíngue francês/ brasileiro, assim como, por osmose familial, um fervoroso admirador do talento de Allais; e desde que soube as minhas "primeiras letras", vi-me na obrigação moral de chamar a mim a responsabilidade de tentar verter numa língua acessível aos brasileiros do século XXI o inenarrável estilo do mestre, do qual trago uma amostra aqui.

Escolhi "Les Templiers" entre cerca de cinquenta traduções que fiz de Allais pelos seguintes motivos: o próprio autor o selecionou como um de seus cinco melhores contos. Embora não tenha sido o mais árduo de traduzir, mostrou possuir um bom grau de dificuldade quando me esforcei para respeitar os "coq-à-l'âne" estilísticos tão característicos da prosa de Allais que passa de uma linha à outra de uma espécie de homenagem de Victor Hugo (A noite caia, a procela se desencadeava. Ha! Que bela idéia havíamos tido de ir contemplar o seu azul, ô, Mediterrâneo!) aos mais óbvios lugares comuns (Será que a administração, cá entre nós, não poderia pôr placas de trânsito em todas as ilhas do Mediterrâneo, pois é muito difícil para achar o seu caminho, quando não se está acostumado?), de profundas indagações filosóficas (Schwartzbacher dizia: "procuremos uma saída", mas ele queria dizer: "procuremos uma entrada".) à chula linguagem de soldado (Remar abre o apetite! Caramba, que almoço! Lembro notoriamente um certo presunto cujo osso foi raspado até a indecência.), e tudo isso em menos de mil palavras!

É claro que também escolhi "Les templiers" pelo seu extraordinário final, a sua "chute". 


\section{Os Templários}

Le parapluie de l'escouade, 1893

Este aí era um cara, e um cara porreta, e de prontidão. Vinte vezes eu o vi, apenas apertando o lombo do cavalo entre os joelhos, parar todo o esquadrão, de primeira.

Ele era cabo, naqueles tempos. Um pouco implicante no serviço, mas um verdadeiro doce, na cidade.

Como era mesmo que ele se chamava? Um desses benditos nomes alsacianos que não me volta à memória, do tipo: Wurtz, ou Schwartz.... É, creio que é isso, Schwartz. Ademais, o nome em nada altera os fatos. Natural de NeufBrisach, não de Neuf-Brisach propriamente dita, mas dos arrabaldes.

Que cara, esse Schwartz.

Um domingo (estávamos aquartelados em Oran) pela manhã, Schwartz me disse: "O que vamos fazer hoje?". Eu respondo: "O que você quiser, meu velho Schwartz".

Então ficamos de acordo para dar um passeio no mar.

Pegamos um barco, e força nos remos marujos! E logo estávamos ao largo.

O tempo estava bom, um pouco de vento, mas bom tempo mesmo assim.

Seguíamos a nossa derrota como dardos, felizes em ver sumir a costa da África no horizonte.

Remar abre o apetite! Caramba, que almoço!

Lembro notoriamente um certo presunto cujo osso foi raspado até a indecência.

Enquanto isto, não notávamos que a brisa anuviava e que o marulho se tornava inquietante.

- Cáspite, disse Schwartz, seria bom...

Por falar nisto, não... Não era Schwartz que ele se chamava. Ele tinha um nome maior que isso, algo assim como Schwartzbach. Schwartzbach, que seja!

Então, Schwartzbach me disse: "Meu filho, temos que pensar em aterrar".

Mas que aterrar, que nada! $\mathrm{O}$ vento virara temporal.

A vela é levada por uma borrasca, um remo vai-se embora, arrastado por um vagalhão. Estamos à mercê das ondas. 
Estávamos nos afastando da costa com uma deplorável velocidade e trambolhões terríveis.

Prontos para tudo, nós tínhamos tirado as nossas botas e os nossos casa$\cos$.

A noite caía, a procela se desencadeava.

Ha! Que bela ideia havíamos tido de ir contemplar o seu azul, ô, Mediterrâneo!

E depois, a escuridão se fez completa. Era perto da meia-noite.

De súbito, um estalido apavorante. Acabávamos de tocar em terra.

Onde estávamos?

Schwartzbach, ou melhor, Schwartzbacher, pois acabei de lembrar, é Schwartzbacher; Schwartzbacher, digo eu, que conhece a sua geografia como o sujo da unha dos dedos (os alsacianos são muito instruídos) me disse:

- Estamos na ilha de Rodes, meu velho.

Será que a administração, cá entre nós, não poderia pôr placas de trânsito em todas as ilhas do Mediterrâneo, pois é muito difícil para achar o seu caminho, quando não se está acostumado?

Estava escuro como dentro de um forno. Molhados como sopas, trepamos nos rochedos da falésia.

Nem uma luz no horizonte. Que beleza!

- Vamos perder a chamada de amanhã de manhã - eu disse, para dizer algo.

- E até a da noite - respondeu soturnamente Schwartzbacher.

E andávamos entre os tojos magros e as giesteiras eriçadas. Andávamos sem saber onde, apenas para nos aquecermos.

- Há! Gritou Schwartzbacher, estou vendo um clarão, vedes, acolá?

Segui a direção do dedo de Schwartzbacher, e, de fato, um clarão brilhava, mas muito longe, um clarão esquisito.

Não eram os simples lumes de uma casa, não era o fulgor de uma aldeia, não, era um clarão esquisito.

E retomamos a nossa marcha, acelerando-a.

Chegamos, enfim.

Nessas rochas se erguia um castelo de aspecto imponente, um alto castelo de pedra, onde não se parecia rir amiúde. 
Uma das torres desse castelo servia de capela, e o clarão que tínhamos visto nada mais era que a resplandecência sacra filtrada pelos altos vitrais góticos.

Cantos chegavam até nós, cantos graves e varonis, cantos que punham arrepios pelas costas.

- Entremos - fez Schwartzbacher, resoluto.

- Por onde?

- Ah! Aí está... procuremos uma saída.

Schwartzbacher dizia: "procuremos uma saída", mas ele queria dizer: "procuremos uma entrada". Inclusive, como era a mesma coisa, não achei necessário fazer-lhe observar o seu erro relativo, que talvez não passasse de um lapso causado pelo frio.

Realmente, tinha entradas, mas todas estavam fechadas, e nada de campainhas. Então, era como se não tivesse entradas.

Finalmente, de tanto dar a volta ao castelo, descobrimos um murinho que pudemos escalar.

- Agora, disse Schwartzbacher, procuremos a cozinha.

Provavelmente não tinha cozinha no prédio, pois nenhum cheiro de guisado veio acariciar as nossas narinas.

Passeávamos por corredores intermináveis e entrelaçados. Vez ou outra, o vôo de um morcego roçava os nossos rostos com a sua imunda pelúcia.

No viés de uma betesga, os cantos que ouvíramos soaram aos nossos ouvidos, chegando de muito perto.

Estávamos num grande cômodo que devia comunicar com a capela.

- Estou vendo o que é - disse Schwartzbacher (melhor dizendo: Schwartzbachermann, acabei de lembrar), estamos no castelo dos Templários.

Ele mal terminara estas palavras, quando uma imensa porta de ferro escancarou-se.

Fomos inundados de luz.

Homens estavam de joelhos, algumas centenas, vestidos de ferro, capacete na cabeça, e de alta estatura.

Eles se ergueram com um longo tumulto de ferragens, se voltaram e nos viram.

Então, a um só gesto, sacaram da espada e marcharam sobre nós, com a lâmina alta. 
Eu teria preferido estar alhures.

Sem se desconcertar, Schwartzbachermann arregaçou as mangas, se colocou em postura de defesa, e gritou com uma voz forte:

- Homessa! Senhores Templários, ainda vocês fossem cem mil... Ou não me chamo Durand ${ }^{3}$ !

Ah! Acabei de lembrar agora, era Durand que ele se chamava. Seu pai era alfaiate em Aubervilliers". Durand, sim, é isso mesmo...

Velho Durand! Caracas, que cara!

\section{Les Templiers}

Le parapluie de l'escouade, 1893

En voilà un qui était un type, et un rude type, et d'attaque! Vingt fois je l'ai vu, rien qu'en serrant son cheval entre ses cuisses, arrêter tout l'escadron, net.

Il était brigadier à ce moment-là. Un peu rosse dans le service, mais charmant, en ville.

Comment diable s'appelait-t-il? Un sacré nom alsacien qui ne peut pas me revenir, comme Wurtz ou Schwartz... Oui, ça doit être ça, Schwartz. Du reste, le nom ne fait rien à la chose. Natif de Neufbrisach, pas de Neufbrisach même, mais des environs.

Quel type, ce Schwartz!

Un dimanche (nous étions en garnison à Oran), le matin, Schwartz me dit: "Qu'est-ce que nous allons faire aujourd'hui?" Moi, je lui réponds: "Ce que tu voudras, mon vieux Schwartz."

Alors nous tombons d'accord sur une partie en mer.

Nous prenons un bateau, souque dur, garçons! et nous voilà au large.

Il faisait beau temps, un peu de vent, mais beau temps tout de même.

Nous filions comme des dards, heureux de voir disparaître à l'horizon la côte d'Afrique.

Ça creuse, l'aviron! Nom d'un chien, quell déjeuner!

3 Na França, arquétipo de sobrenome com alta abrangência; o mesmo que Da Silva no Brasil.(NDT)

4 Subúrbio do norte de Paris. (NDT) 
Je me rappelle notamment un certain jambonneau qui fut ratissé jusqu’à l'indécence.

Pendant ce temps-là, nous ne nous apercevions pas que la brise fraîchissait et que la mer se mettait à clapoter d'une façon inquiétante.

- Diable! dit Schwartz, il faudrait...

Au fait, non, ce n'est pas Schwartz qu'il s'appelait. Il avait un nom plus long que ça, comme qui dirait Schwartzbach. Va pour Schwartzbach!

Alors Schwartzbach me dit : «Mon petit, faut songer à rallier. »

Mais je t'en fiche, de rallier. Le vent soufflait en tempête.

La voile est enlevée par une bourrasque, un aviron fiche le camp, emporté par une lame. Nous voilà à la merci des flots.

Nous gagnions le large avec une vitesse déplorable et un cahotement terrible.

Prêts à tout événement, nous avions enleve nos bottes et notre veste.

La nuit tombait, l'ouragan faisait rage.

Ah! une jolie idée que nous avions eue là, d'aller contempler ton azur, ô Méditerranée!

Et puis, l'obscurité arrive complètement. Il n'était pas loin de minuit.

Tout à coup, un craquement épouvantable. Nous venions de toucher terre.

Où étions-nous?

Schwartzbach, ou plutôt Schwartzbacher, car je me rappelle maintenant, c'est Schwartzbacher; Schwartzbacher, dis-je, qui connaissait sa géographie sur le bi du bout du doigt (les Alsaciens sont très instruits), me dit :

- Nous sommes dans l'île de Rhodes, mon vieux.

Est-ce que l'administration, entre nous, ne devrait pas mettre des plaques indicatrices sur toutes les îles de la Méditerranée, car c'est le diable pour s'y reconnaitre, quand on n'a pas l'habitude?

Il faisait noir comme dans un four. Trempés comme des soupes, nous grimpâmes les rochers de la falaise.

Pas une lumière à l'horizon. C'était gai.

- Nous allons manquer l'appel de demain matin, dis-je, pour dire quelque chose.

- Et même celle du soir, répondit sombrement Schwartzbacher.

Et nous marchions dans les petits ajoncs maigres et dans les genêts piquants. Nous marchions sans savoir où, uniquement pour nous réchauffer. 
- Ah! s'écria Schwartzbacher, j’aperçois une lueur, vois-tu, là-bas?

Je suivis la direction du doigt de Schwartzbacher, et effectivement une lueur brillait, mais très loin, une drôle de lueur.

Ce n'était pas une simple lumière de maison, ce n'étaient pas des feux de village, non, c'était une drôle de lueur.

Et nous reprîmes notre marche, en l'accélérant.

Nous arrivâmes, enfin.

Sur des rochers se dressait un château d'aspect imposant, un haut château de pierre, où l'on n'avait pas l'air de rigoler tout le temps.

Une des tours de ce château servait de chapelle, et la lueur que nous avions aperçue n'était autre que l'éclairage sacré tamisé par lês hauts vitraux gothiques.

Des chants nous arrivaient, des chants graves et mâles, des chants qui vous mettaient des frissons dans le dos.

- Entrons, fit Schwartzbacher, résolu.

- Par où?

- Ah! voilà... cherchons une issue.

Schwartzbacher disait : " Cherchons une issue », mais il voulait dire : « Cherchons une entrée. » D'ailleurs, comme c'est la même chose, je ne crus pas devoir lui faire observer son erreur relative, qui peut-être n'était qu'un lapsus cause par le froid.

Il y avait bien des entrées, mais elles étaient toutes closes, et pas de sonnettes.

Alors c'est comme s'il n'y avait pas eu d'entrées.

À la fin, à force de tourner autour du château, nous découvrîmes un petit mur que nous pûmes escalader.

- Maintenant, fit Schwartzbacher, cherchons la cuisine.

Probablement qu'il n'y avait pas de cuisine dans l'immeuble, car aucune odeur de fricot ne vint chatouiller nos narines.

Nous nous promenions par des couloirs interminables et enchevêtrés. Parfois, une chauve-souris voletait et frôlait nos visages de sa sale peluche.

Au détour d'un corridor, les chants que nous avions entendus vinrent frapper nos oreilles, arrivant de tout près.

Nous étions dans une grande pièce qui devait communiquer avec la chapelle.

- Je vois ce que c'est, fit Schwartzbacher (ou plutôt Scwhartzbachermann, je me souviens maintenant), nous nous trouvons dans le château des Templiers. 
Il n’avait pas terminé ces mots, qu'une immense porte de fer s'ouvrit toute grande.

Nous fûmes inondés de lumière.

Des hommes étaient là, à genoux, quelques centaines, bardés de fer, casque en tête, et de haute stature.

Ils se relevèrent avec un long tumulte de ferraille, se retournèrent et nous virent. latte haute.

Alors, du même geste, ils firent Sabre-main! et marchèrent sur nous, la

J'aurais bien voulu être ailleurs.

Sans se déconcerter, Schwartbachermann retroussa ses manches, se mit en posture de défense et s'écria d'une voix forte:

-Ah! nom de Dieu! messieurs les Templiers, quand vous seriez cent mille... aussi vrai que je m'appelle Durand...!

Ah! je me rappelle maintenant, c'est Durand qu'il s'appelait. Son père était tailleur à Aubervilliers. Durand, oui, c'est bien ça...

Sacré Durand, va! Quel type!

\section{Referências}

ALLAIS, Alphonse: CEuvres Anthumes. Paris: Robert Laffont, Collection Bouquins, 1990. CARRIÈRE, Jean-Claude. Anthologie de l'humour 1900. Paris: Les Éditions 1900, 1988. 